[Agr. Biol. Chem., Vol. 35, No. 13, p. 2043 2049, 1971]

\title{
Studies on the Decarboxylation of Amino Acids with Glyoxal ${ }^{\dagger}$
}

\author{
By Masao Fujimaki, Nguyen Van Chuyen and Tadao Kurata \\ Department of Agricultural Chemistry, Faculty of Agriculture, \\ The University of Tokyo, Tokyo \\ Received June 21, 1971
}

\begin{abstract}
Decarboxylation of about twenty kinds of $\alpha, \beta$ and $\gamma$-amino acids in the reaction with glyoxal or ninhydrin was investigated. The decarboxylation rate of amino acids proved that steric and polar effects had important roles in the reaction.

From the data of $\mathrm{p} K_{2}$ values and decarboxylation rates of amino acids, it can be concluded that under a similar steric environment, the decarboxylation rate depends on the anion concentration of amino acids.

Besides carbon dioxide, acetaldehyde, 2-propanone and propionaldehyde were respectively detected from the reaction of $\beta$-alanine, $\beta$ and $\gamma$-amino- $n$-butyric acids with glyoxal or ninhydrin. The decarboxylation mechanism of these amino acids seemed to take place through the corresponding $\beta$ - or $\gamma$-keto acid.

Oxygen absorption was also observed from the reaction of amino acids with dicarbonyl compounds.
\end{abstract}

Carbon dioxide is generated, when food is heated or stored for a certain period of time. This phenomenon is mainly based on the reaction of aldehydic monosaccharide with amino acids in aqueous solutions as reported by Maillard. "' Carbon dioxide and acetaldehyde were also identified by Strecker ${ }^{2}$ as the reaction products of alanine with alloxan. Volatile carbonyl compounds and carbon dioxide from $\alpha$-amino acids through Strecker degradation are considered to participate in the formation of cooked flavors of food and in flavor deterioration during food preservation.

Van Slyke et al. ${ }^{31}$ studied the decarboxyla-

$\dagger$ Studies on the Reaction of Amino Acids with Dicarbonyl Compounds, Part I.

This report was presented in part at the Annual Meeting of the Agricultural Chemical Society of Japan, Fukuoka, April, 1970.

1) L. C. Maillard, Comp. Rend., 155, 1554 (1912); Ann. Chim., 5, 258 (1916).

2) A. Strecker, Ann., 123, 363 (1862).

3) D. D. Van Slyke, R. T. Dillon, D. A. McFayden and P. Hamilton, J. Biol. Chem., 141, 627 (1941). tion of various amino acids in the reactions of amino acids with ninhydrin. Hereafter various studies on the decarboxylation of amino acids were reported. ${ }^{4-101}$ However, no detailed report has been found on the relation of decarboxylation to the structure of the amino acids.

The present paper deals with investigations on the decarboxylation of amino acids in the reaction with glyoxal or ninhydrin. Relations of the decarboxylation rate to the chemical structure of the amino acids were also discussed.

4) F. H. Stadtman, C. O. Chichester and G. Mackinney, J. Am. Chem. Soc., 74, 3194 (1952).

5) E. W. Chappelle and J.M. Luck, J. Biol. Chem., 229, 171 (1957).

6) K. Dose, Chem. Ber., 90, 1251 (1957).

7) G.W. Stevention and J. M. Luck, J. Biol. Chem., 236, 715 (1961).

8) G. Chatelus, Bull. Soc. Chem. France, 1965, 929; ibid., 1964, 2523.

9) S. J. Cole, J. Food Science, 32, 245 (1967).

10) A. F. Al-Sayyab and A. Lawson, J. Chem. Soc., 1968,406 . 


\section{MATERIALS AND METHODS}

Reagent. All amino acids used in this research are guaranteed reagents of Kanto Chemical Co., Ltd. or Tokyo Chemical Co., Ltd. Glyoxal ( $400^{\circ}$ aqueous solution) and ninhydrin (guaranteed reagent) are also of Kanto Chemical Co., Ltd. DL-Alanine-1-14C was supplied by the Daiichi Pure Chemical Co., Ltd. through the Japan Radioisotope Association. Deionized water was used in all of the experiments.

Reaction condition. Amino acids (0.4 mmole) and glyoxal (20.0 mmole) were reacted in $4 \mathrm{ml}$ of an acetate buffer solution $(0.5 \mathrm{~N}, \mathrm{pH} 5.0)$ at $50^{\circ} \mathrm{C}$.

Measurement of generated carbon dioxide and absorbed oxygen quantities. Since decarboxylation and oxygen absorption occurred at the same time, a direct method11) with Warburg manometers was used to measure carbon dioxide generated at 20,30, 40 , and $50 \mathrm{~min}$ of the reaction time. Carbon dioxide generated from the reaction of amino acids ( $0.04 \mathrm{mmole})$ with ninhydrin ( 0.4 mmole) was measured by Warburg manometers at $2,4,6$, and $8 \mathrm{~min}$ of the reaction time. The amount of oxygen absorbed by the reaction of amino acids $(0.4 \mathrm{mmole})$ with glyoxal $(20.0 \mathrm{mmole})$ was also measured by the above-mentioned method with hyamine* $(0.3 \mathrm{ml})$ as an absorption reagent2* for carbon dioxide. The generated ${ }^{14} \mathrm{CO}_{2}$ was measured after trapping with hyamine. Hyamine $(0.3 \mathrm{ml})$ was put into the center well of a Warburg manometer flask. After the reaction, hyamine was diluted with dioxane scintillator $\left(\mathrm{PPO}^{3 *} \mathrm{~g}\right.$, POPOP* $25 \mathrm{mg}$, napthalene $10 \mathrm{~g}$ and dioxane $100 \mathrm{ml}$ ) to $10 \mathrm{ml}$, and radioactivity was measured by a liquid scintillation spectrometer (Horiba, type LS-500).

Measurement of $p K_{2}$. The $\mathrm{p} K_{2}$ of amino acids was measured at $50^{\circ} \mathrm{C}$ by using an automatic titrator (Hiranuma Sangyo, Rat type lP).

11) W. W. Umbreit, R. H. Burris and J. F. Stauffer, "Manometric method," 4th ed. Burgess publishing company, 1964, p. 28.

* Hyamine $(\mathrm{OH}): \quad p$-(di-isobutylcresoxyethoxyethyl)-dimethylbenzyl-ammonium hydroxide.

2* In this experiment, $10 \%$ and $20 \% \mathrm{KOH}$ were also tested as carbon dioxide absorption reagents, but hyamine seemed to be the most suitable one under the above-mentioned condition.

3* PPO: 2,5-diphenyloxazole.

4* POPOP: 2,2-p-phenylene-bis-(5-phenyloxazole).

\section{Detection of carbonyl compounds}

Gas chromatography. Gas chromatography was conducted on a Shimadzu gas chromatograph (Model GC -4A) equipped with a hydrogen flame detector by using nitrogen as a carrier gas. Stainless steel columns $(300 \mathrm{~cm} \times 3 \mathrm{~mm})$ packed with $20 \%$ carbowax $20 \mathrm{M}$ on Diasolid $\mathrm{L}(60 \sim 80$ mesh) were used.

Thin-layer chromatography. The 2,4-dinitrophenylhydrazone derivatives of generated carbonyl compounds were prepared by a usual method. Toluene was used as a developing solvent and Silicagel $G$ was used as an adsorbent.

Measurement of browning. Browning of an amino acid-glyoxal solution was measured at $470 \mathrm{~m} \mu$ with a spectrophotometer (Hitachi-Model 101).

\section{RESULTS AND DISCUSSION}

Stadman et al." found that over $80 \%$ of carbon dioxide was derived from the carboxyl group of amino acid and less than $10 \%$ came from sugar in the reaction between glucose and glycine.

Cole $^{9)}$ also reported that carbon dioxide was formed mainly by Strecker degradation but another unidentified pathway was also available for the formation of carbon dioxide from sugars in the presence of amino compounds.

In this research we also studied the origin of carbon dioxide from the reaction between amino acid and glyoxal by using Warburg manometers and tracer technique. The result shown in Table I revealed that almost all carbon dioxide was derived from the carboxyl

Table I. Yields of Carbon Dioxide From aN Amino Acid-glyoxal Solution at $50^{\circ} \mathrm{C}$, $\mathrm{pH} 5.0$ FOR ONE HR

\begin{tabular}{ccc}
\hline $\begin{array}{c}\text { DL-Alanine } \\
\text { (or DL-ala-1-14 } \mathrm{C} \text { ) } \\
\text { at 0 time }\end{array}$ & Generated $\mathrm{CO}_{2}$ & $\begin{array}{c}\mathrm{CO}_{2} \text { (mmole) } \\
\mathrm{Ala} \text { (mmole) }\end{array}$ \\
\hline $0.30 \mathrm{mmole}$ & $0.0033 \mathrm{mmole}^{a)}$ & $1.1 \%$ \\
$21,875 \mathrm{cpm}$ & $303 \mathrm{cpm}^{b}$ & $1.3 \%$ \\
\hline
\end{tabular}

a) $\mathrm{CO}_{2}$ was measured by a Warburg manometer.

b) ${ }^{14} \mathrm{CO}_{2}$ was measured by a liquid scintillation spectrometer. 
Table II. $\mathrm{p} K_{2}$ Values and Rates of Amino Acids in the Reaction With GLyoxal OR NinhydRIN at $50^{\circ} \mathrm{C}$, pH 5.0

\begin{tabular}{|c|c|c|c|c|}
\hline \multirow{2}{*}{ Amino acid } & \multirow{2}{*}{ Substituent } & \multicolumn{2}{|c|}{ Rate $(\mu \mathrm{mole} / \mathrm{min})$} & \multirow{2}{*}{$\begin{array}{c}\mathrm{p} K \\
\left(\text { at } 50^{\circ} \mathrm{C}\right)\end{array}$} \\
\hline & & Glyoxal & Ninhydrin & \\
\hline$\alpha$-Aminoisobutyric acid & $\left(\mathrm{CH}_{3}\right)_{2-}$ & 0.058 & 0 & 9.72 \\
\hline DL-Alanine & $\mathrm{CH}_{3}$ & 0.070 & 0.310 & 9.42 \\
\hline L-Serine & $\mathrm{HO}-\mathrm{CH}_{2-}^{-}$ & 0.075 & 0.562 & - \\
\hline L-Valine & $\left(\mathrm{CH}_{3}\right)_{2}-\mathrm{CH}-$ & 0.083 & 0.333 & 9.40 \\
\hline DL- $\alpha$-Amino- $n$-butyric acid & $\mathrm{CH}_{3}-\mathrm{CH}_{2-}$ & 0.100 & 0.340 & 9.34 \\
\hline L-Isoleucine & $\mathrm{CH}_{3}-\mathrm{CH}_{2}-\left(\mathrm{CH}_{3}\right) \mathrm{CH}-$ & 0.112 & 0.350 & 9.39 \\
\hline Glycine & $\mathrm{H}-$ & 0.125 & 0.520 & 9.34 \\
\hline L-Glutamic acid & $\mathrm{HOOC}-\mathrm{CH}_{2}-\mathrm{CH}_{2-}$ & 0.133 & 0.790 & $9.67^{a 1}$ \\
\hline DL-Norvaline & $\mathrm{CH}_{3}-\mathrm{CH}_{2}-\mathrm{CH}_{2-}$ & 0.137 & 0.479 & 9.34 \\
\hline L-Leucine & $\left(\mathrm{CH}_{3}\right)_{2}-\mathrm{CH}-\mathrm{CH}_{2^{-}}$ & 0.175 & 0.625 & 9.38 \\
\hline L-Aspartic acid & $\mathrm{HOOC}_{-}-\mathrm{CH}_{2-}-$ & 0.200 & 1.125 & $9.60^{01}$ \\
\hline DL-Lysine $\cdot \mathrm{HCl}$ & $\mathrm{H}_{2} \mathrm{~N}-\left(\mathrm{CH}_{2}\right)_{4-}^{-}$ & 0.216 & 0.541 & 8.86 \\
\hline L-Phenylalanine & $\mathrm{C}_{6} \mathrm{H}_{5}-\mathrm{CH}_{2}$ & 0.225 & 0.854 & 一 \\
\hline L-Glutamine & $\mathrm{H}_{2} \mathrm{~N}-\mathrm{CO}-\left(\mathrm{CH}_{2}\right)_{2-}$ & 0.233 & 0.854 & 8.85 \\
\hline L-Asparagine & $\mathrm{H}_{2} \mathrm{~N}-\mathrm{CO}-\mathrm{CH}_{2^{-}}$ & 0.275 & 0.833 & 8.67 \\
\hline L-Ornithine $\cdot \mathrm{HCl}$ & $\mathrm{H}_{2} \mathrm{~N}_{-}\left(\mathrm{CH}_{2}\right)_{3-}$ & 0.300 & 0.687 & 8.44 \\
\hline L-Methionine & $\mathrm{CH}_{3}-\mathrm{S}-\mathrm{CH}_{2}-$ & 0.316 & 0.875 & - \\
\hline
\end{tabular}

a) Data at $25^{\circ} \mathrm{C}$. J. P. Greenstein and M. Winitz, "Chemistry of the Amino Acids," John Wiley \& Sons Ltd., 1961, p. 487 .

group of amino acid.

Since amino acids used in this research do not contain any substituents which are attached to $\alpha$-carbon with a double bond, the resonance effect can be negligible. Hence, steric and polar effects are considered as main factors having influence on the reaction. Yields of generated carbon dioxide against time are shown in Fig. 1. At the first stage of the reaction, generated carbon dioxide had a linear relationship with time. Slopes of these straight lines were calculated and the result is shown in Table II.

As Schönberg et al. reported, ${ }^{121}$ the decarboxylation mechanism of an amino acid with a dicarbonyl compound is considered to be as follows:

12) A. Schönberg, R. Moubacher and A. Mostafa, J. Chem. Soc., 1948, 176.

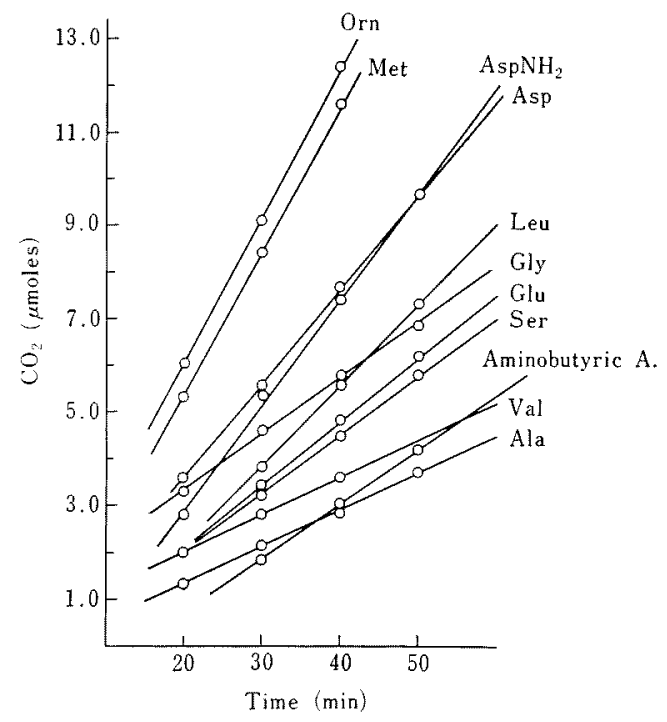

FIG. 1. Carbon Dioxide Generation in the Reaction of Various Amino Acids (0.4 mmole) with Glyoxal (20.0 mmole) at $50^{\circ} \mathrm{C}, \mathrm{pH} 5.0$. 


$$
\begin{aligned}
& \begin{array}{l}
\mathrm{R}-\mathrm{C}=\mathrm{O} \\
\mathrm{R}-\mathrm{C}=\mathrm{O}
\end{array}+\begin{array}{c}
\mathrm{NH}_{2}-\stackrel{1}{\mathrm{C}}-\mathrm{COOH} \\
\mathrm{H}
\end{array} \longrightarrow \begin{array}{l}
\mathrm{R} \\
\mathrm{R}-\mathrm{C}=\mathrm{N}-\mathrm{C}-\mathrm{COOH} \\
\mathrm{R}-\mathrm{C}=\mathrm{O} \mathrm{H}
\end{array} \\
& \begin{array}{l}
\mathrm{R} \\
\mathrm{R}-\mathrm{C}-\mathrm{N}=\stackrel{+}{\mathrm{C} H}+ \\
\mathrm{R}-\stackrel{1}{\mathrm{C}}-\mathrm{OH}
\end{array}+\mathrm{CO}_{2}
\end{aligned}
$$

Therefore, both steric and polar effects in the decarboxylation are thought to participate in the formation and/or decarboxylation of the Schiff base.

At any given $\mathrm{pH}$, the concentration of the amino acid anion, the reactive species to the carbonyl group, is governed by the equation (1).

$$
\mathrm{pH}=\mathrm{p} K_{2}+\log \frac{\left[\mathrm{A}^{-}\right]}{\left[\mathrm{HA}^{ \pm}\right]}
$$

(A- the amino acid anion; HA \pm the zwitterion)

According to this equation, when $\mathrm{pH}$ value is fixed, the rate of the reaction will increase with the decrease of $\mathrm{p} K_{2}$ value, because the smaller the $\mathrm{p} K_{2}$, the higher the anion concentration. The result in Table II reveals that with a similar steric environment, amino acids with a high anion concentration give a higher decarboxylation rate as shown in the cases of asparagine and glutamine, lysine and ornithine, aspartic acid and glutamic acid. In these cases, the electron withdrawing property of the substituents i.e. the $\varepsilon$-amino group of lysine or the $\beta$-carboxyl group of aspartic acid decreases electron density at $\alpha$ carbon and nitrogen atoms and also contributes to decrease $\mathrm{p} K_{2}$ value, and the effect is weakened by the interception of methylene units.

The result shown in Table II also indicates that amino acids with an alkyl chain have the following relations in the decarboxylation rate: Leu $>$ Nor $>$ Ileu $>$ Amino- $n$-butyric acid $>$ $\mathrm{Val}>\mathrm{Ala}>$ Aminoisobutyric acid.

In this case, since the differences in the basicity of alkyl chain amino acids are rather small, the observed decarboxylation rate order can not be explained by $\mathrm{p} K_{2}$ alone. For in- stance, novraline and amino- $n$-butyric acid have the same $\mathrm{p} K_{2}$ value, but they differ in the rate from one another.

Ingold-Taft equation (2) was used to examine the substituent effect on the decarboxylation rate of these alkyl chain amino acids.

$$
\log \frac{\mathrm{k}_{\mathrm{R}}}{\mathrm{k}_{\mathrm{CH}}}=\rho^{*} \cdot \sigma^{*}
$$

$\left(\mathrm{k}_{\mathrm{R}} / \mathrm{k}_{\mathrm{CH}_{3}}\right.$ rate ratio; $\rho^{*}$ constant of the reaction; $\sigma^{*}$ polar effect constant. $\sigma^{*}$ values were picked up from reference (14))

The result shown in Fig. 2 indicates that the logarithms of the relative rates have a linear relationship with $\sigma^{*}$ values under a similar steric environment, and two series of amino acids, Leu $>$ Nor $>$ Amino- $n$-butyric acid and Ileu $>$ Val which have a primary or secondary alkyl substituent on $\alpha$-carbon atom, respectively, have fairly similar $\rho^{*}$ values. Decarboxylation of Schiff base which has a double-bonded nitrogen atom in the $\alpha$-position is considered to take place through its unionized acid, ${ }^{131}$ possibly via the formation of an unionized chelated ring structure, ${ }^{15)}$ and electron donating substituents will decrease its anion concentration and facilitate the production of carbon dioxide through heterolytic fission. The apparent deviation of straight lines for secondary alkyl substituted series. from that for primary alkyl substituted series can be ascribed to the different steric environment of these two series.

On the other hand, the decarboxylation rates of the series of amino acids, Gly $>$ Ala $>$ Aminoisobutyric acid, clearly show that steric effect at $\alpha$-carbon atom has a much pronounced influence on the reactivity of the amino group, and decarboxylation of amino-

13) L.W. Clark, "The Chemistry of Carboxylic Acids and Esters," ed. by S. Patai, John Wiley \& Sons Ltd., 1969, p. 591.

14) M.S. Newman, "Steric Effect in Organic Chemistry," John Wiley \& Sons Ltd., 1956, p. 559.

15) F. H. Westheimer and W. A. Jones, J. Am. Chem. Soc., 63, 3283 (1941). 


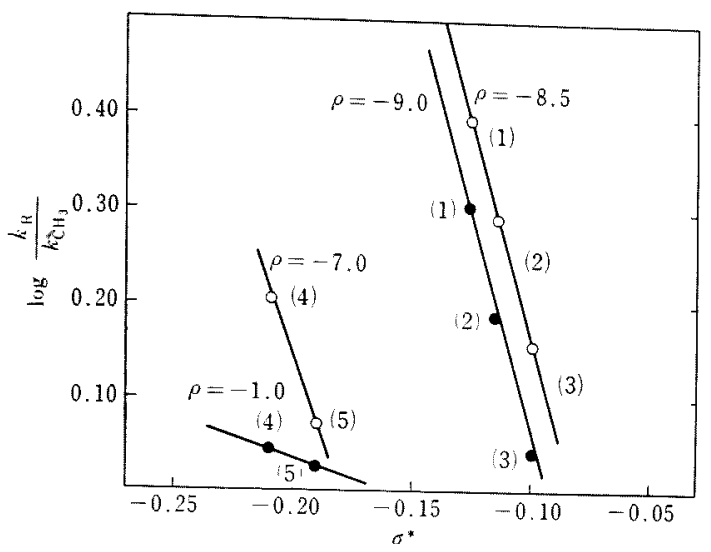

FIG. 2. Log Plot for Relative Rates of Decarboxy* lation vs. $\sigma^{*}$.

(1) Leu, (2) Nor, (3) Amino-n-butyric acid, (4) Ileu, (5) Val; O: Amino acid + Glyoxal, : Amino acid + Ninhydrin.

TABLE III. DECARBOXYLATION RATE-Ratios IN THE REACTION OF AMINO ACIDS WITH GLYOXAL OR NINHYDRIN AT $50^{\circ} \mathrm{C}, \mathrm{pH} 5.0$

\begin{tabular}{lcc}
\hline \multirow{2}{*}{ Amino acid } & \multicolumn{2}{c}{ Dicarbonyl compound } \\
\cline { 2 - 3 } & Glyoxal & Ninhydrin \\
\hline Alanine & $1.00 a$ & 1.00 \\
Amino-n-butyric acid & 1.42 & 1.10 \\
Valine & 1.18 & 1.07 \\
Isoleucine & 1.60 & 1.12 \\
Norvaline & 1.95 & 1.54 \\
Leucine & 2.50 & 2.01 \\
Aminoisobutyric acid & 0.82 & 0.00 \\
\hline
\end{tabular}

a) These figures indicate decarboxylation rate ratio.

isobutyric acid which has two methyl groups on $\alpha$-carbon decreased considerably.

To compare reactivities of amino acids to glyoxal with those to a carbonyl compound of stronger reactivity, ninhydrin was used in the study. Decarboxylation rates were shown in Table II. Although there are some discrepancies, the rate orders of the two reaction systems are very similar to one another, especially in the case of alkyl chain amino acids. The ratio of the decarboxylation rate of alkyl chain amino acids was calculated with alanine as a standard (Table III). The differences in the rate-ratio and $\rho^{*}$ values (Fig. 2) for these two reaction system may be explained as the differences between the chemical structures of glyoxal and ninhydrin. The steric effect of ninhydrin, can be considered as the causative factor, since the aromatic ring system of ninhydrin is relatively rigid and nonflexible, and it required less hindered amino groups than glyoxal did. The clearest evidence was shown in the case of aminoisobutyric acid. The rate-ratio was 0.82 with glyoxal but seemed to be negligible with ninhydrin.

Decarboxylation of cysteine, histidine, tryptophane, threonine had no linear relation to time (Fig. 3). According to Friedman et al. ${ }^{16)}$ cysteine was not only decomposed by

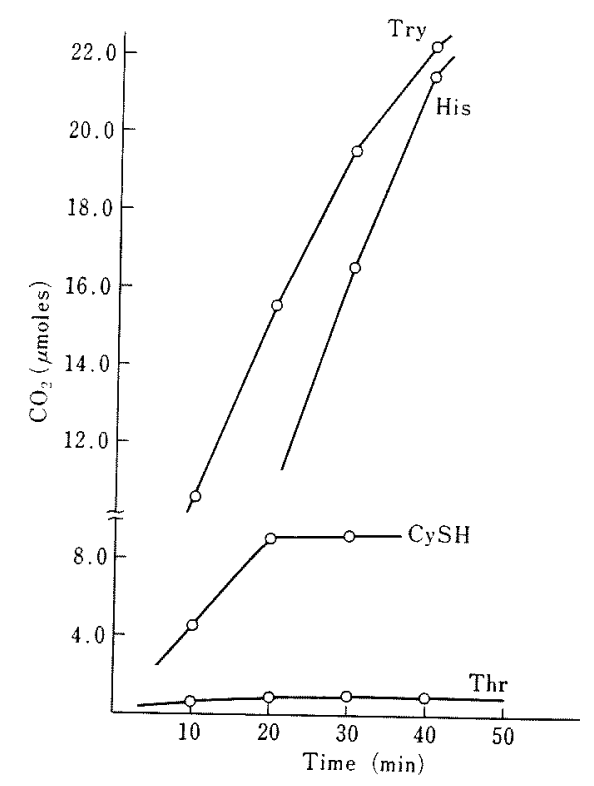

FIG. 3. Carbon Dioxide Generation in the Reaction of Try, His, CySH and Thr with Glyoxal at $50^{\circ} \mathrm{C}$, pH 5.0 .

16) M. Friedman and C. W. Sigel, Biochem., 5, $478(1966)$. 
Strecker degradation, but also by other pathways. This may explain why decarboxylation of cysteine had a high rate only at the beginning stage of the reaction. Histidine had a high rate in comparison with other amino acids. The reactivity of the $\mathrm{NH}$ group in the imidazole ring of this acid appeared to be the main cause, ${ }^{16}$ but the exact decarboxylation mechanism was unknown. Tryptophane is an unstable amino acid, and it can be degraded into kynurenine, 3-oxy-kynurenine, anthranilic acid.... ${ }^{17}$ When glyoxal reacts with tryptophane, these products may also take a part in decarboxylation, which may be the reason why tryptophane produced a lot of carbon dioxide as compared with other amino acids.

Until $50 \mathrm{~min}$ of the reaction time, decarboxylation of serine had a linear relation to time, but threonine did not have such a relation. Yield of carbon dioxide from threonine was smaller than that from serine. This fact was still inexplicable.

As Schönberg et al. ${ }^{12)}$ described in their paper, only $\alpha$-amino acids were reactive in Strecker degradation. According to Van Slyke et al. ${ }^{31} 0.16$ mole of carbon dioxide was generated from $\beta$-alanine $(1$ mole) in the reaction with ninhydrin at $100^{\circ} \mathrm{C}$ for $6 \mathrm{~min}$.

In this research, carbon dioxide generation was also observed from the reactions of $\beta$ alanine, and $\beta$ - or $\gamma$-amino- $n$-butyric acid with glyoxal (Fig. 4).

Acetaldehyde, 2-propanone, and propionaldehyde were detected from $\beta$-alanine, and $\beta$-or $\gamma$-amino- $n$-butyric acid respectively by gas chromatography and thin-layer chromatography (Table IV). Self ${ }^{181}$ reported that $\beta$-amino acids also undergo oxidative deamination and decarboxylation to ketone with one less

17) S. Akabori and S. Mizushima, "Chemistry of Protein," Vol. II, Kyoritsu Shuppan Co., Ltd., 1954, p. 562 .

18) R. Self, "Chemistry and Physiology of Flavor," ed. by H. W. Schultz, E. A. Day and L. M. Libbey, the AVI publishing company, Inc. 1967, p. 364.

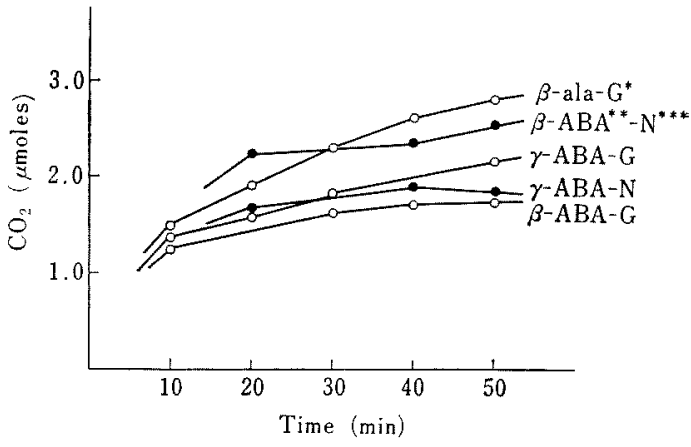

FIG. 4. Decarboxylation of $\beta$-Ala, $\beta$ - and $\gamma$-Amino$n$-butyric Acid in the Reaction with Ninhydrin or Glyoxal.

* Glyoxal.

2* Amino- $n$-butyric acid.

$3 *$ Ninhydrin.

Table IV. Retention time and $R f$ Values of Products from $\beta$-ALANINE, $\beta$ - AND $\gamma$-AMINo- $n$ BUTYRIC ACID WITH GLYOXAL OR NINHYDRIN AT $100^{\circ} \mathrm{C}$, pH 5.0 FOR $30 \mathrm{MIN}$

\begin{tabular}{|c|c|c|c|c|}
\hline \multicolumn{2}{|c|}{ Solution } & Product & $\begin{array}{l}\text { Retention }{ }^{a} \\
\text { time (min) }\end{array}$ & $R f^{b l}$ \\
\hline$\beta$-Ala- & $\left\{\begin{array}{l}\text { Ninhydrin } \\
\text { Glyoxal }\end{array}\right.$ & $\begin{array}{l}\text { Acetaldehyde } \\
\text { " }\end{array}$ & $\begin{array}{c}5.20 \\
\prime \prime\end{array}$ & $\begin{array}{c}0.30 \\
\prime \prime\end{array}$ \\
\hline$\beta-A B A-c)$ & $\left\{\begin{array}{l}\text { Ninhydrin } \\
\text { Glyoxal }\end{array}\right.$ & $\begin{array}{c}\text { 2-Propanone } \\
\text { " }\end{array}$ & $\begin{array}{c}7.10 \\
11\end{array}$ & $\begin{array}{c}0.25 \\
\prime \prime\end{array}$ \\
\hline \multirow[t]{2}{*}{$\gamma-\mathrm{ABA}-$} & & $\begin{array}{c}\text { Propional- } \\
\text { dehyde }\end{array}$ & 8.20 & 0.34 \\
\hline & (Glyoxal & " & " & $\left.-{ }^{d}\right)$ \\
\hline
\end{tabular}

a) Conditions; Column: 209\% Carbowax $20 \mathrm{M}$ on Diasolid L $(60 \sim 80 \mathrm{mesh}) 300 \mathrm{~cm} \times 3 \mathrm{~mm}$ i.d.; Temperature: $60^{\circ} \mathrm{C}$, Carrier gas : nitrogen $\left(1.0 \mathrm{~kg} / \mathrm{cm}^{2}\right)$; Detection: hydrogen ionization detector.

b) Thin-layer chromatography of 2,4-DNPH derivatives; Adsorbent: Silicagel G; Developing solvent: toluene.

o) ABA: Amino-n-butyric acid.

d) The existence of 2,4 DNPH was not positively confirmed.

carbon, e.g., $\beta$-amino- $n$-butyric acid produced 2-propanone.

Although the detailed mechanism of the decarboxylation reaction of $\beta$ - or $\gamma$-amino acid in the presence of $\alpha$-dicarbonyl compounds is not known, decarboxylation may take place 


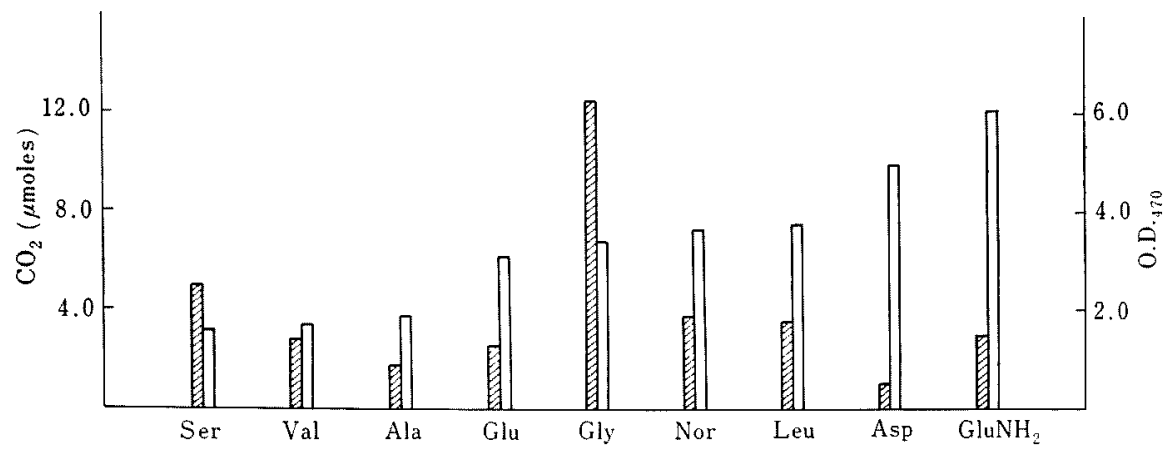

FIG. 5. Carbon Dioxide Production and Browning of Amino Acid-Glyoxal Solutions.

$$
\text { Browning, } \square \text { : Amount of } \mathrm{CO}_{2} \text {. }
$$

through the corresponding $\beta$ - or $\gamma$-keto acid.

In the reactions between amino acids and dicarbonyl compounds (glyoxal, ninhydrin), besides decarboxylation, oxygen absorption was also observed. Amino reductone and brown polymer, the melanoidin were formed in the process of the reaction. Oxygen might be consumed in the oxidation of reductone and/or in the oxidative degradation of melanoidin. ${ }^{19}$ Details of this phenomenon will be reported in the next paper.

Quantities of carbon dioxide generated and results of browning measurements are shown in Fig. 5. The results suggest that decarboxylation and the development of browning might occur in separate pathways, since there were some amino acids which developed intense browning but yielded a small amount of carbon dioxide.

19) H. Kato, N. Gomyo, N. Kirigaya and M. Fujimaki, Abstract of papers, Annual Meeting of the Agricultural Chemical Society of Japan, Fukuoka, April, 1970, p. 368. 